\title{
Implementasi Data Mining Dalam Memprediksi Jumlah Pinjaman Dengan Algoritma C4.5 Pada Kopdit CU Damai Sejahtera
}

\author{
Sri Devi Manullang, Efori Buulolo, Ikhwan Lubis \\ Program Studi Teknik Informatika, STMIK Budi Darma, Medan, Indonesia \\ Email: sridevimanullang14@gmail.com
}

\begin{abstract}
Abstrak-Perkembangan teknologi informasi saat ini memungkinkan penyimpanan data dalams kala yang sangat besar. Perkembangan ini telah menambah keberbagai bidang, termasuk kopdit, sehingga pemanfaatan teknologi informasi di lembaga masyarakat luas. Data mining merupakan kegiatan yang meliputi pengumpulan pemakaian data historis untuk menemukan keteraturan pola, atau hubungan dalam data berukuran besar. Adapun proses memprediksi jumlah pinjaman nasabah selama ini yang ada di koperasi simpan pinjam masih berdasarkan melihat langsung jumlah pinjaman nasabahnya dan meliha tcatatan buku besar yang ada di koperasi tersebut. Penerapan algoritma C4.5 merupakan suatu solusi pemecahan kasus yang sering digunakan dalam pemecahan masalah pada teknik klasifikasi yang memiliki karakteristik yaitu dengan proses penentuan nilai entropy dan nilai gain dari kemungkinan setiap kriteria yang menjadi acuan keputusan yang dilanjutkan dengan proses hasil dari pohon keputusan.
\end{abstract}

Kata Kunci: Data Mining, Algoritma C4.5, Prediksi, Jumlah Pinjaman, Pohon Keputusan.

Abstract-The development of information technology now allows storing data in a very large time. This development has added to various fields, including credit facilities, so that the use of information technology in public institutions. Data mining is an activity that includes gathering the use of historical data to find the regularity of patterns, or relationships in large data. The process of predicting the number of customer loans so far in the savings and loan cooperatives is still based on looking directly at the loan amount of the customers and seeing the general ledger records in the cooperative. The application of the C4.5 algorithm is a case-solving solution that is often used in problem solving on classification techniques that have characteristics namely by the process of determining the entropy value and gain value from the possibility that each criterion is a reference decision followed by the process of the decision tree.

Keywords: Data Mining, C4.5 Algorithm, Prediction, Loan Amount, Decision Tree.

\section{PENDAHULUAN}

Kopdit CU. Damai Sejahtera adalah koperasi sebuah lembaga keuangan yang bergerak di bidang simpan pinjam yang dimiliki dan dikelola oleh anggotanya yang bertujuan untuk menyejahterahkan anggotanya sendiri. Koperasi simpan pinjam atau biasa disebut koperasi kredit merupakan suatu bentuk koperasi yang berdiri sendiri dimana anggota-anggotanya adalah orang-orang atau badan-badan yang tergabung dalam koperasi tersebut.

Perkembangan teknologi komputer sangatlah pesat pada saat ini dimana untuk dapat memenuhi kebutuhan dan kemudahan dalam pencarian, penyajian, dan penanganan data. Hampir semua aspek kegiatan manusia saat ini berhubungan dengan komputer, mulai dari kegiatan perkantoran, perbankan, perdagangan, pendidikan, bisnis, dan sebagainya. Sebagai lembaga keuangan yang berfungsi untuk menyimpan dana dari masyarakat dan menyalurkannya melalui bentuk pinjaman, pada Kopdit CU. Damai Sejahtera berusaha untuk memberikan kemudahan dalam setiap layanan yang diberikan misalnya dalam layanan pinjaman bagi seorang nasabah. Namun dalam pengambilan keputusan pemberian jumlah pinjaman kadang kurang tepat, seperti lebih besar dana yang dimohon untuk dipinjam dari pada jumlah tabungan nasabah, dan jumlah pinjaman tergantung pada penghasilan nasabah jika penghasilan nasabah tersebut memenuhi cicilan pinjaman pembayaran perbulannya maka pinjaman akan diberikan.

Dalam pengambilan keputusan yang dilakukan oleh koperasi bukan hanya memberikan pinjaman saja melainkan mereka harus melihat resiko, faktor-faktor dalam pembayaran pinjaman yang diajukan oleh nasabah tersebut, karena resiko dalam pengambilan keputusan dalam menentukan jumlah pinjaman adalah resiko yang sangat tinggi. Untuk mengurangi resiko tersebut keyakinan atau kemampuan dan kesanggupan nasabah untuk membayar atau melunasi hutangnya sesuai dengan yang diperjanjikan dalam peminjaman harus sangat diperhatikan. Untuk membantu permasalahan diatas, dimanfaatkan teknik data mining algoritma C4.5 untuk pengambilan keputusan dalam menentukan jumlah pinjaman [1] .

Penerapan algoritma C4.5 merupakan satu solusi pemecahan kasus yang sering digunakan dalam pemecahan masalah pada teknik klasifikasi yang memiliki karakteristik yaitu dengan proses penentuan nilai entropy dan nilai gain dari kemungkinan setiap kriteria yang menjadi acuan keputusan yang dilanjutkan dengan proses hasil dari pohon keputusan. Tingkat akurasi yang didapatkan menggunakan algoritma $\mathrm{C} 4.5$ ini sudah cukup tinggi, oleh karena itu dapat disimpulkan algoritma ini cocok untuk diimplementasikan pada penelitian kali ini tentang memprediksi jumlah pinjaman [2].

Melihat latar belakang masalah yang ada maka diperlukan sebuah sistem menggunakan algoritma C4.5 yang dapat membantu pihak lembaga terkait khususnya Kopdit CU. Damai Sejahtera dalam menentukan atau mempredikasi jumlah pinjaman untuk para nasabah atau anggota yang hendak meminjam. 


\section{METODE PENELITIAN}

\subsection{Data Mining}

Data mining adalah proses yang memperkerjakan satu atau lebih teknik pembelajaran komputer (machine learning) untuk menganalisis dan mengekstraksi pengetahuan (knowledge) secara otomatis. Knowledge Discovery in Databases (KDD) adalah penerapan metode saintifik pada data mining. Dalam konteks ini data mining merupakan satu langkah dari proses KDD [4].

\subsection{Pinjaman}

Kredit adalah pinjaman uang atau tagihan yang dapat dipersamakan dengan itu berdasarkan persetujuan atau kesepakatan pinjam-meminjam antara koperasi dan pihak nasabahnya yang mewajibkan pihak peminjam untuk melunasi. Imbalan, atau pembagian hasil keuntungan. Hal yang termasuk dalam pengertian kredit yangdiberikan adalah kredit dalampembelian surat berharga nasabah yang dilengkapi dengan Note Purchase Agreement [8]

\subsection{Nasabah}

Berdasarkan Undang-Undang Republik Indonesia No. 21 tahun 2008 tentang pebankan Syariah nasabah adalah pihak yang menggunakan jasa bank syariah dan atau Unit Usaha Syariah. Nasabah penyimpan adalah nasabah yang menempatkan dananya di Bank Syariah dan atau Unit Usaha Syariah dalam bentuk simpanan berdasarkan akad antara bank syariah atau Unit Usaha Syariah dan nasabah yang bersangkutan [9].

\subsection{Pohon Keputusan (Decision Tree)}

Pohon keputusan merupakan metode klasifikasi dan prediksi yang sangat terkenal. Metode pohon keputusan mengubah fakta yang sangat besar menjadi pohon keputusan yang merepresentasikan aturan. Aturan dapat dengan mudah dipahami dengan bahasa alami, juga dapat diekspresikan dalam bentuk bahasa basis data seperti Structured Query Language untuk mencari record pada kategori tertentu. Pohon keputusan juga berguna untuk mengeksplorasi data, menemukan hubungan tersembunyi antara sejumlah calon variabel input dengan sebuah variabel target. Karena pohon keputusan memadukan antara eksplorasi data dan pemodelan, pohon keputusan sangat bagus sebagai langkah awal dalam proses pemodelan bahkan ketika dijadikan sebagai model akhir dari beberapa teknik lain [10].

\subsection{Algoritma C4.5}

Secara umum Algoritma C4.5 untuk membangun pohon keputusan adalah sebagai berikut [10]:

1. Pilih atribut sebagai akar

2. Buat cabang untuk masing-masing nilai

3. Bagi kasus dalam cabang

4. Ulangi proses untuk masing-masing cabang sampai semua kasus pada cabang memiliki kelas yang sama.

Data yang dimiliki harus disusun menjadi sebuah tabel berdasarkan kasus dan jumlah responden sebelum dilakukan perhitungan untuk mencari nilai entropy dan gain.

$\operatorname{Entropy}(S)=\sum_{i=0}^{n}-\mathrm{pi} * \log ^{2} \quad p i$

Rumus (2) merupakan rumus yang digunakan dalam perhitungan entropy yang digunakan untuk menentukan seberapa informatif atribut tersebut. Berikut keterangannya [11]:

$S$ : Himpunan kasus

$n$ :Jumlah partisi $S$

pi :Jumlah kasus pada partisi ke-i

$\operatorname{Gain}(S, A)=\operatorname{Entropy}(S)-\sum_{i=1}^{n} \frac{|s i|}{|s|} * \operatorname{Entropy}(S i)$

Rumus (1) merupakan rumus yang digunakan dalam perhitungan gain setelah melakukan perhitungan entropy. Berikut keterangannya [11]:

$S$ : Himpunan kasus

A : Atribut

$n$ : Jumlah partisi atribut A

$|S i|$ : Jumlah kasus pada partisi ke-i

$|S|$ : Jumlah kasus dalam $S$ 


\section{HASIL DAN PEMBAHASAN}

Analisa data pinjaman dilakukan setelah data terkumpul dan sesuai dengan kebutuhan sistem ini. Salah satu cara untuk melakukan analisa pinjaman adalah dengan melakukan klasifikasi dari kumpulan data calon peminjam. Salah satu model klasifikasi adalah dengan membuat pohon keputusan. Analisa yang tersebut dilakukan berdasarkan teknik algoritma C4.5 dengan beberapa langkah yang sudah ditentukan. Data yang diambil merupakan data pinjaman nasabah tahun 2016 dan 2017 pada Kopdit CU. Damai Sejahtera dan dapat dilihat pada Tabel 1.

Tabel 1. Data Pinjaman Nasabah

\begin{tabular}{|c|c|c|c|c|c|c|c|c|}
\hline Nama & Alamat & Pekerjaan & Penghasilan & $\begin{array}{l}\text { Simpanan } \\
\text { Saham }\end{array}$ & $\begin{array}{l}\text { Nilai } \\
\text { Agunan }\end{array}$ & $\begin{array}{l}\text { Jenis } \\
\text { Pinjaman }\end{array}$ & $\begin{array}{l}\text { Status } \\
\text { Anggota }\end{array}$ & $\begin{array}{l}\text { Jlh } \\
\text { Pinjaman }\end{array}$ \\
\hline $\begin{array}{l}\text { Esra Ronasari } \\
\text { Rajagukguk, SE }\end{array}$ & $\begin{array}{l}\text { Jl.Sisingamangaraja } \\
\text { No. } 10-\mathrm{A}\end{array}$ & Direktur & Tinggi & Tinggi & Tinggi & Agunan & Tetap & Tinggi \\
\hline $\begin{array}{l}\text { Ridawati } \\
\text { Manik, S.Kom }\end{array}$ & J1.Perhubungan & Manager & Tinggi & Tinggi & Tinggi & Agunan & Tetap & Tinggi \\
\hline $\begin{array}{l}\text { Mia Berliana } \\
\text { Br.Manullang }\end{array}$ & Jl. Martoba I & Wiraswasta & Medium & Standart & Sedang & Biasa & Tetap & Standart \\
\hline $\begin{array}{l}\text { Darmi } \\
\text { Tinambunan }\end{array}$ & Jl.Selambo No.5A & Karyawan & Rendah & Rendah & Sedang & Biasa & Baru & Standart \\
\hline $\begin{array}{l}\text { Efendi } \\
\text { Manullang }\end{array}$ & $\begin{array}{l}\text { Jl.Patumbak gg.Sutra } \\
\text { No. } 14\end{array}$ & Petani & Rendah & Rendah & Sedang & Biasa & Tetap & Standart \\
\hline $\begin{array}{l}\text { Ira Ulita } \\
\text { Marbun }\end{array}$ & J1.Martoba II No.22 & Karyawan & Medium & Standart & Sedang & Biasa & Baru & Standart \\
\hline $\begin{array}{l}\text { Waty } \\
\text { Lumbangaol }\end{array}$ & Jl.Perhubungan & Wiraswasta & Tinggi & Tinggi & Tinggi & Agunan & Tetap & Standart \\
\hline $\begin{array}{l}\text { Saimah } \\
\text { Pasaribu }\end{array}$ & J1.Dame No.02 & Manager & Tinggi & Tinggi & Tinggi & Agunan & Tetap & Tinggi \\
\hline $\begin{array}{l}\text { Bestaria } \\
\text { Pangaribuan }\end{array}$ & Pasar 12 No. 30 & Direktur & Tinggi & Tinggi & Tinggi & Agunan & Tetap & Tinggi \\
\hline $\begin{array}{l}\text { Erbarison } \\
\text { Nababan }\end{array}$ & Jl.Selambo Toba No.7 & Manager & Tinggi & Tinggi & Tinggi & Agunan & Tetap & Standart \\
\hline Liza & $\begin{array}{l}\text { Jl.Lukah gg.Calung } \\
\text { No.11 }\end{array}$ & Wiraswasta & Medium & Tinggi & Tinggi & Agunan & Tetap & Standart \\
\hline $\begin{array}{l}\text { Kasmawita } \\
\text { Manalu }\end{array}$ & Pasar 12 No.9 & Karyawan & Rendah & Rendah & Sedang & Biasa & Tetap & Standart \\
\hline $\begin{array}{l}\text { Diana } \\
\text { Manurung }\end{array}$ & Jl.Perbatasan Pasar 12 & Karyawan & Medium & Tinggi & Tinggi & Agunan & Tetap & Tinggi \\
\hline $\begin{array}{l}\text { Lenny Marlina } \\
\text { Nababan }\end{array}$ & Jl.Martoba II No.18 & Karyawan & Rendah & Rendah & Sedang & Biasa & Baru & Standart \\
\hline Grey Silaban & $\begin{array}{l}\text { J1.Biola Desa Amplas } \\
\text { No.01 }\end{array}$ & Petani & Medium & Standart & Tinggi & Agunan & Tetap & Standart \\
\hline $\begin{array}{l}\text { Saida } \\
\text { Tinambunan }\end{array}$ & J1. Pasar 14 & Wiraswasta & Rendah & Standart & Sedang & Biasa & Baru & Standart \\
\hline $\begin{array}{l}\text { Pardamean } \\
\text { Manullang }\end{array}$ & J1.Pertahanan No.25 & PNS & Tinggi & Tinggi & Tinggi & Agunan & Baru & Tinggi \\
\hline $\begin{array}{l}\text { Raguel } \\
\text { Sihombing }\end{array}$ & JL.Mandolin No.05 & Manager & Tinggi & Tinggi & Tinggi & Agunan & Tetap & Tinggi \\
\hline Aro Lahagu & J1.Selambo No.5 & Wiraswasta & Tinggi & Tinggi & Tinggi & Biasa & Tetap & Tinggi \\
\hline $\begin{array}{l}\text { Hagsler } \\
\text { Matondang }\end{array}$ & Dusun IV No.23 & Karyawan & Tinggi & Tinggi & Sedang & Biasa & Tetap & Standart \\
\hline $\begin{array}{l}\text { Moy Sari } \\
\text { Sinaga }\end{array}$ & $\begin{array}{l}\text { J1.Selambo Raya } \\
\text { No.05 }\end{array}$ & Karyawan & Rendah & Rendah & Sedang & Biasa & Tetap & Standart \\
\hline $\begin{array}{l}\text { Edwin } \\
\text { Tumanggor }\end{array}$ & Jl.Cendana No.20 & Karyawan & Rendah & Tinggi & Sedang & Biasa & Baru & Standart \\
\hline $\begin{array}{l}\text { Yolanda } \\
\text { Sianturi }\end{array}$ & $\begin{array}{l}\text { J1.Tanjung Morawa } \\
\text { gg.Setia No. } 15\end{array}$ & Petani & Rendah & Standart & Sedang & Biasa & Tetap & Standart \\
\hline $\begin{array}{l}\text { Vera Sany } \\
\text { Tobing }\end{array}$ & $\begin{array}{l}\text { Dusun III-A Desa } \\
\text { Amplas }\end{array}$ & PNS & Medium & Standart & Sedang & Biasa & Tetap & Standart \\
\hline $\begin{array}{l}\text { Ester Dewi } \\
\text { Dyana Sinaga }\end{array}$ & $\begin{array}{l}\text { J1.Piano Desa Amplas } \\
\text { No. } 21\end{array}$ & Karyawan & Medium & Rendah & Sedang & Biasa & Baru & Standart \\
\hline $\begin{array}{l}\text { Bintora } \\
\text { Alwisius } \\
\text { Silaban }\end{array}$ & $\begin{array}{l}\text { Jl.Keramat Kuda } \\
\text { No.01 }\end{array}$ & Manager & Tinggi & Tinggi & Tinggi & Agunan & Tetap & Tinggi \\
\hline $\begin{array}{l}\text { Ronald } \\
\text { Situmeang }\end{array}$ & J1.Teratai No.03 & Manager & Tinggi & Tinggi & Tinggi & Agunan & Baru & Tinggi \\
\hline $\begin{array}{l}\text { Esna Uli } \\
\text { Pakpahan }\end{array}$ & Jl.Turi amplas & Petani & Medium & Standart & Sedang & Biasa & Baru & Standart \\
\hline Rony Hasibuan & J1.Pertahanan No. 25 & PNS & Medium & Standart & Sedang & Biasa & Tetap & Standart \\
\hline $\begin{array}{l}\text { Kristian } \\
\text { Supriadi } \\
\text { Sihombing }\end{array}$ & $\begin{array}{l}\text { Jl.Cendana ASRI } \\
\text { No. } 15\end{array}$ & Direktur & Tinggi & Tinggi & Tinggi & Agunan & Tetap & Tinggi \\
\hline
\end{tabular}


Klasifikasi merupakan suatu proses untuk menyatakaan suatu objek ke salah satu kategori yang sudah didefenisikan sebelumnya. Data nasabah yang akan dicari hubungannya meliputi proses penghasilan, Simpanan Saham, Nilai agunan, jenis Pinjaman, status Anggota, Adapun variable yang akan diproses mining yang didapat dari Kopdit CU. Damai Sejahtera meliputi :

1. Penghasilan

Tabel 2. Klasifikasi Penghasilan Nasabah

\begin{tabular}{cc}
\hline Kelas & Penghasilan Nasabah \\
\hline Low & $<=2,5 \mathrm{jt}$ \\
Medium & $2,51 \mathrm{jt}-4,99 \mathrm{jt}$ \\
High & $>5 \mathrm{jt}$ \\
\hline
\end{tabular}

2. Simpanan Saham

Tabel 3. Klasifikasi Simpanan Saham Nasabah

\begin{tabular}{cc}
\hline Kelas & Simpanan Saham \\
\hline Rendah & $<=1 \mathrm{jt}-2 \mathrm{jt}$ \\
Standart & $2,1 \mathrm{jt}-5 \mathrm{jt}$ \\
Tinggi & $>5,1 \mathrm{jt}$
\end{tabular}

3. Nilai Agunan

Tabel 4. Klasifikasi Nilai Agunan Nasabah

\begin{tabular}{cc}
\hline Kelas & Nilai Agunan Nasabah \\
\hline Sedang & $<=1-9 \mathrm{jt}$ \\
Tinggi & $>10 \mathrm{jt}$ \\
\hline
\end{tabular}

4. Jenis Pinjaman

Jenis Pinjaman yaitu :

a. Biasa : Pinjaman yang tidak perlu menyertakan agunan sebagai penjamin pembayaran atau yang biasa dikenal sebagai pinjaman tanpa agunan.

b. Agunan : Pinjaman yang menyerahkan agunan berupa asset milik nasabah untuk menjamin pelunasan kredit yang diterima.

5. Status Anggota

Tingkat kebutuhan setiap orang pasti berbeda tetapi jelas tingkat kebutuhanan antara orang menikah dengan belum menikah pasti berbeda. Bagi nasabah yang tetap akan lebih di prioritaskan untuk meminjam dari pada untuk nasabah baru akan dipertimbangkan terlebih dahulu karena belum diketahui karakter dari nasabah tersebut.

6. Layak / Tidak Layak

Adapun penentuan Layak atau Tidak layak yaitu :

a. Jika Pinjaman tanpa Agunan / Biasa syarat nya adalah :

1. Aktif Menabung selama 6 bulan berturut-turut.

2. Pinjaman Maksimal 2 jt diatas simpanan.

b. Jika Pinjaman Menggunakan Agunan

1. Aktif Menabung selama 6 bulan berturut-turut.

2. Pinjaman Maksimal $70 \%$ dari nilai agunan.

7. Jumlah Pinjaman

Setelah mengetahui kriteria yang ada, maka kita bisa melihat jumlah pinjaman yang ingin dipinjam oleh nasabah.

Tabel 5. Klasifikasi Jumlah Pinjaman Nasabah

\begin{tabular}{cc}
\hline Kelas & Pinjaman yang dapat Dicairkan \\
\hline Standart & $<=1 \mathrm{jt}-9 \mathrm{jt}$ \\
Tinggi & $>10 \mathrm{jt}$ \\
\hline
\end{tabular}

Menghitung jumlah pinjaman nasabah, antara lain penghasilan, simpanan saham, nilai agunan, jenis pinjaman, status anggota dan entropy dari semua atribut. Hasil perhitungan dapat dilihat pada Tabel 6.

Baris total kolom entropy pada tabel 6. dihitung dengan persamaan diabah ini sebagai berikut :

$$
\begin{aligned}
& \operatorname{Entropy}(S)=\sum_{i=0}^{n}-\text { pi } * \log ^{2} p i \\
& \text { Entropy }(\text { Total })=\left(-\frac{11}{30} * \log 2\left(\frac{11}{30}\right)\right)+\left(-\frac{19}{30} * \log 2\left(\frac{19}{30}\right)\right)
\end{aligned}
$$




$$
=0,948078242
$$

Sementara itu, nilai entropy pada baris nilai agunan dihitung seperti dibawah ini:

Entropy (nilai agunan-tinggi) $=\left(-\frac{11}{15} * \log 2\left(\frac{11}{15}\right)\right)+\left(-\frac{4}{15} * \log 2\left(\frac{4}{15}\right)\right)$

$$
=0,8366407419
$$

Entropy (nilai agunan-sedang $)=\left(-\frac{0}{15} * \log 2\left(\frac{0}{15}\right)\right)+\left(-\frac{15}{15} * \log 2\left(\frac{15}{15}\right)\right)$

$$
=0,503258334
$$

$\operatorname{Gain}($ Total $)=0,948078242-\left(\frac{15}{30} * 0,8366407419\right)+\left(\frac{15}{30} * 0,\right)$

\begin{tabular}{|c|c|c|c|c|c|c|c|}
\hline \multirow{2}{*}{ Node } & & \multirow{2}{*}{ Ket } & \multirow{2}{*}{$\begin{array}{c}\text { Jumlah } \\
\text { (S) }\end{array}$} & \multicolumn{2}{|c|}{ Jumlah Pinjaman } & \multirow{2}{*}{ Entropy } & \multirow{2}{*}{ Gain } \\
\hline & & & & Tinggi & Standart & & \\
\hline \multirow[t]{18}{*}{1} & Total & & 30 & 11 & 19 & 0,948078242 & \\
\hline & Penghasilan & & & & & & 0,45938248 \\
\hline & & High & 13 & 10 & 3 & 0,779349837 & \\
\hline & & Medium & 9 & 1 & 8 & 0,503258334 & \\
\hline & & Low & 8 & 0 & 8 & 0 & \\
\hline & Simpanan Saham & & & & & & 0,41730059 \\
\hline & & Tinggi & 17 & 11 & 6 & 0,936667381 & \\
\hline & & Standart & 8 & 0 & 8 & 0 & \\
\hline & & Rendah & 5 & 0 & 5 & 0 & \\
\hline & Nilai Agunan & & & & & & 0,529757871 \\
\hline & & Tinggi & 15 & 11 & 4 & 0,8366407419 & \\
\hline & & Sedang & 15 & 0 & 15 & 0 & \\
\hline & Jenis Agunan & & & & & & 0,365400004 \\
\hline & & Agunan & 14 & 10 & 4 & 0,8631205677 & \\
\hline & & Biasa & 16 & 1 & 15 & 0,33729 & \\
\hline & Status Anggota & & & & & & $-0,12342197$ \\
\hline & & Tetap & 25 & 11 & 14 & 0,989587521 & 46 \\
\hline & & Baru & 5 & 0 & 5 & 0 & 40 \\
\hline
\end{tabular}

$=0,529757871$

Tabel 6. Perhitungan Node 1

Dari hasil Tabel 6. dapat kita lihat hasil entropy dan gain yang diperoleh dari masing-masing atribut. Dan dapat kita lihat juga hasil pohon keputusan berdasarkan kolom node yang dihasilkan. Pada node pertama dihasilkan variable nilai agunan dengan gain tertinggi yaitu sebesar 0,529757871 sebagai pohon pertama. Pohon pertama ditentukan dari melihat hasil gain terbesar.

Dari hasil tersebut dapat digambarkan pohon keputusan sementara dan dapat dilihat pada Gambar 1. dibawah ini :

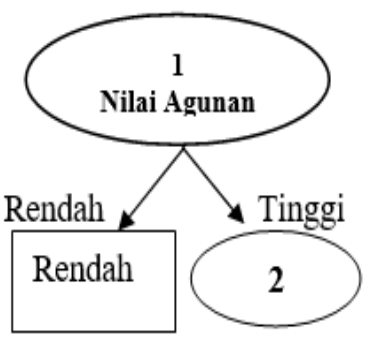

Gambar 1. Pohon Keputusan Hasil Perhitungan Node 1 
Pada Gambar 1. terlihat bahwa nilai agunan berpengaruh dalam proses prediksi jumlah pinjaman nasabah. Dan selanjutnya akan dikembangkan pada Node 2 sampai node ke 7 yaitu Menghitung Atribut dari penghasilanhigh, Jenis Pinjaman, Status Anggota

Menghitung atribut jenis pinjaman, status anggota. Setelah itu melakukan perhitungan gain dari tiap-tiap atribut. Hasil perhitungan dapat dilihat pada tabel 7.

Tabel 7. Perhitungan Node 7

\begin{tabular}{|c|c|c|c|c|c|c|c|}
\hline \multirow[b]{2}{*}{ Node } & & \multirow[b]{2}{*}{ Ket } & \multirow{2}{*}{$\begin{array}{c}\text { Jumlah } \\
\text { (S) }\end{array}$} & \multicolumn{2}{|c|}{ Jumlah Pinjaman } & \multirow[b]{2}{*}{ Entropy } & \multirow[b]{2}{*}{ Gain } \\
\hline & & & & Tinggi & $\begin{array}{c}\text { Standar } \\
\mathrm{t}\end{array}$ & & \\
\hline \multirow[t]{15}{*}{7} & Total & & 2 & 1 & 1 & 1 & \\
\hline & Nilai & & & & & & \\
\hline & Agunan - & & & & & & \\
\hline & Tinggi - & & & & & & \\
\hline & Simpanan & & & & & & \\
\hline & Saham - & & & & & & \\
\hline & Tinggi - & & & & & & \\
\hline & Penghasilan & & & & & & \\
\hline & high- jenis & & & & & & \\
\hline & pinjaman & & & & & & \\
\hline & agunan & & & & & & \\
\hline & Status & & & & & & 0 \\
\hline & Anggota & & & & & & \\
\hline & & Tetap & 2 & 1 & 1 & 1 & \\
\hline & & Baru & 0 & 0 & 0 & 0 & \\
\hline
\end{tabular}

Dari hasil Tabel 7. dapat diketahui bahwa atribut status anggota adalah atribut terakhir Oleh karena itu status anggota menjadi pohon keputusan yang terakhir.Dengan demikian, atribut status anggota menjadi Node cabang dari nilai atribut nilai agunan, simpanan saham, penghasilan dan jenis pinjaman. Dari hasil tersebut dapat digambarkan pohon keputusan akhir dan dapat dilihat pada Gambar 2. dibawah ini :

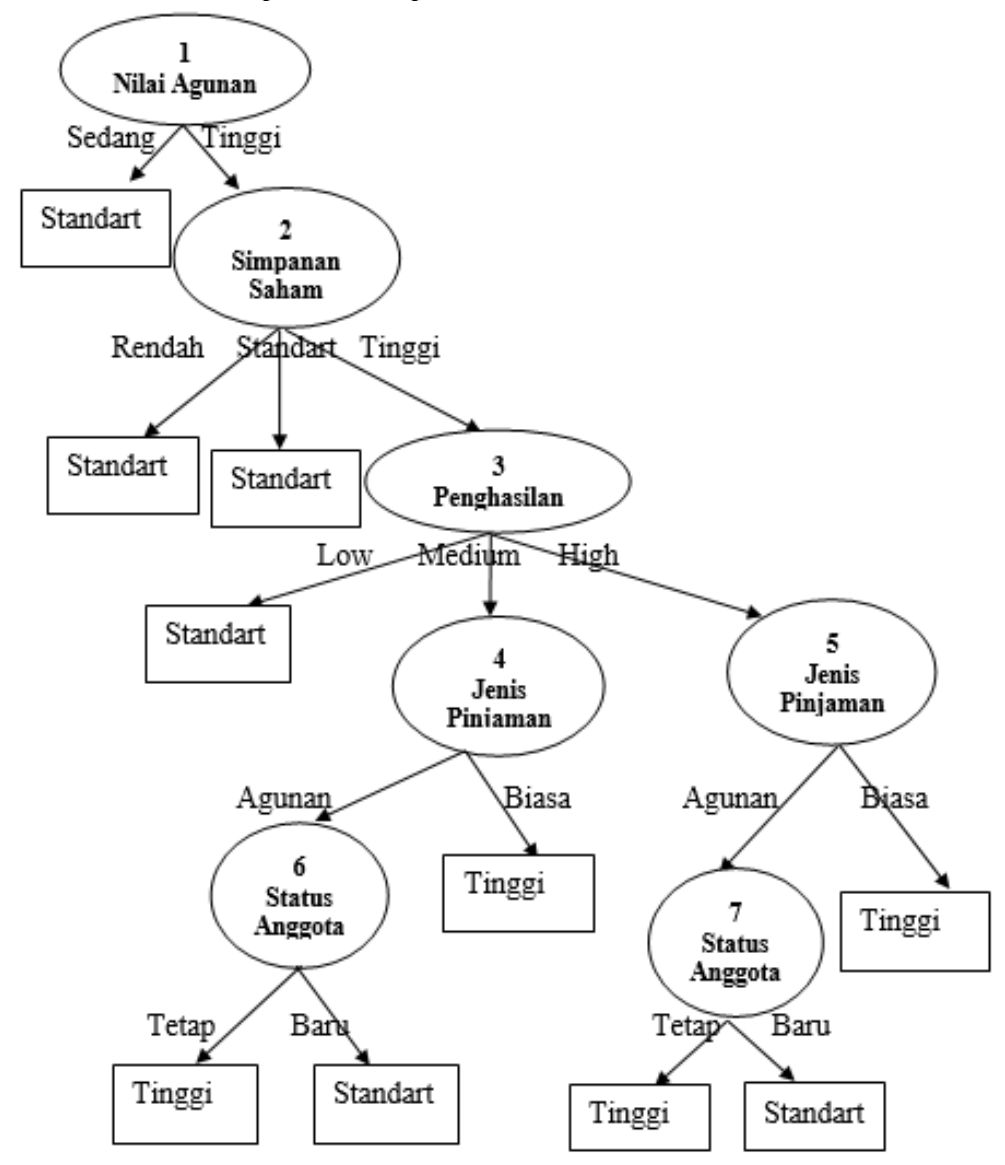

Gambar 2. Pohon Keputusan Hasil Perhitungan Node 7 
Berdasarkan Gambar 2. dapat diambil daftar aturan dari pohon keputusan yaitu :

1. Jika Nilai Agunan Sedang maka jumlah pinjaman Standart

2. Jika Nilai Agunan Tinggi dan Simpanan Saham Rendah maka jumlah pinjaman Standart

3. Jika Nilai Agunan Tinggi dan Simpanan Saham Standart maka jumlah pinjaman Standart

4. Jika Nilai Agunan Tinggi dan Simpanan Saham Tinggi dan Penghasilan Low maka jumlah pinjaman Biasa Standart

5. Jika Nilai Agunan Tinggi dan Simpanan Saham Tinggi dan Penghasilan Medium dan jenis pinjaman Biasa maka jumlah pinjaman Standart.

6. Jika Nilai Agunan Tinggi dan Simpanan Saham Tinggi dan Penghasilan Medium dan jenis pinjaman Agunan dan Status Anggota Tetap maka jumlah pinjaman Tinggi.

7. Jika Nilai Agunan Tinggi dan Simpanan Saham Tinggi dan Penghasilan High maka jumlah pinjaman Biasa Tinggi.

8. Jika Nilai Agunan Tinggi dan Simpanan Saham Tinggi dan Penghasilan High dan jenis pinjaman Agunan dan Status Anggota Baru maka jumlah pinjaman Standart.

9. Jika Nilai Agunan Tinggi dan Simpanan Saham Tinggi dan Penghasilan High dan jenis pinjaman Agunan dan Status Anggota Tetap maka jumlah pinjaman Tinggi.

\subsection{Pengujian}

Hasil implementasi akhir atau output dari aplikasi RapidMiner adalah berupa pohon keputusan atau decision tree/id3. Dari pohon keputusan inilah akan dihasilkan rules atau aturan-aturan yang dapat membantu dalam mengambil keputusan. Pohon keputusan akhir dapat dilihat pada gambar 3. berikut :

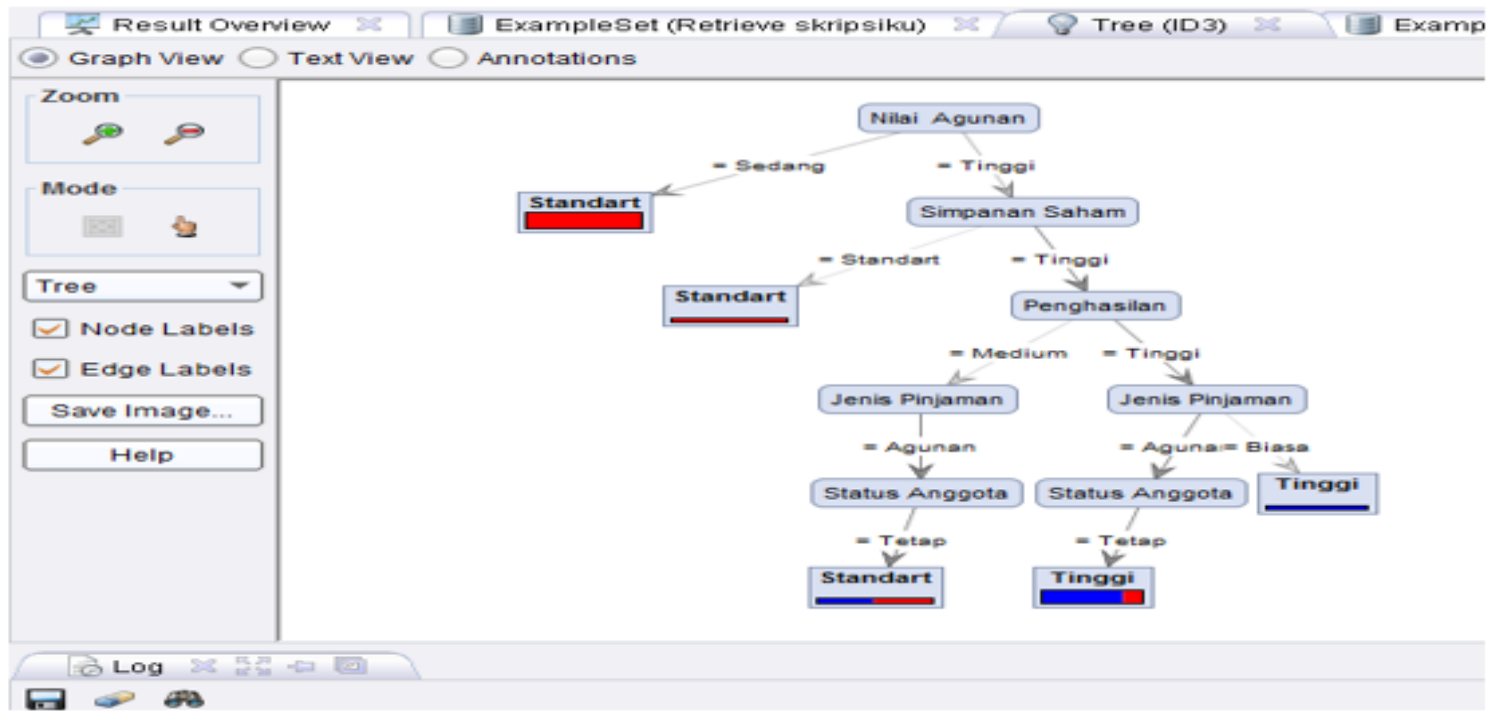

Gambar 3. Tampilan Hasil Pohon Keputusan Pengujian Data

\section{KESIMPULAN}

Sebagai Penutup pembahasan dalam penulisan penelitian ini maka diambil kesimpulan-kesimpulan. Dengan adanya kesimpulan ini dapat diambil suatu perbandingan yang akhirnya dapat memberikan perbaikan-perbaikan pada masa yang akan datang. Adapun kesimpulan yang diperoleh adalah :

1. Dengan menggunakan algoritma C4.5 untuk melakukan perhitungan, ternyata mampu menyelesaikan permasalahan perusahaan dalam memprediksi jumlah pinjaman pada Kopdit CU. Damai Sejahtera.

2. Dengan memanfaatkan data mining meenggunakan algoritma $\mathrm{C} 4.5$ dalam memprediksi jumlah pinjaman, maka dapat dihasilkan bersifat klasifikasi dengan mengubah fakta yang sangat besar menjadi pohon keputusan yang mempresentasikankan aturan.

3. Aplikasi RapidMiner Classification Decision Tree digunakan sebagai aplikasi pendukung keputusan dan pengujian atas hasil yang didapatkan secara manual, yang menghasilkan sebuah pohon keputusan. Dari pohon keputusan inilah akan menghasilkan sebuah aturan-aturan yang dapat membantu pimpinan perusahaan dalam memprediksi jumlah pinjaman. Serta mudah dipahami oleh pengguna aplikasi...

\section{REFERENCES}

[1] L. N. Rani, "Klasifikasi Nasabah Menggunakan Algoritma C4.5 Sebagai Dasar Pemberian Kredit," JURNAL INOVTEK POLBENG SERI INFORMATIKA, vol. VOL. 1, p. 1266, NOVEMBER 2016. 
[2] F. F. Harryanto and S. Hansun, "Penerapan Algoritma C4.5 untuk Memprediksi Penerimaan Calon Pegawai Baru di PT WISE," Jatisi, vol. Vol. 3 No. 2 , p. 96, Maret 2017.

[3] M. "IMPLEMENTASI TEKNOLOGI INFORMASI MENGGUNAKAN HUMAN ORGANIZATION TECHNOLOGY (HOT) FIT MODEL DI PERPUSTAKAAN PERGURUAN TINGGI," JIPI (Jurnal Ilmu Perpustakaan dan Informasi), vol. Vol. 2, p. 226, Tahun 2017.

[4] H. Widayu, S. D. Nasution, N. Silalahi and M. , "DATA MINING UNTUK MEMPREDIKSI JENIS TRANSAKSI NASABAH PADA KOPERASI SIMPAN PINJAM DENGAN ALGORITMA C4.5," MEDIA INFORMATIKA BUDIDARMA, vol. Vo 1, pp. Hal 32-37, Juni 2017.

[5] E. Prasetyo, DATA MINING - Konsep dan Aplikasi Menggunakan MATLAB, Yogyakarta, 2012.

[6] K. and E. T. Luthfi, Algoritma Data Mining, Yogyakarta: C.V ANDI OFFSET (Penerbit ANDI), 2009.

[7] E. Buulolo, "IMPLEMENTASI ALGORITMA APRIORI PADA SISTEM PERSEDIAAN OBAT (STUDI KASUS : APOTIK RUMAH SAKIT ESTOMIHI MEDAN)," Pelita Informatika Budi Darma, vol. Volume : IV, p. 72, Agustus 2013.

[8] R. K. Amin, D. I. M.Si, and Y. S. M,T, "IMPLEMENTASI KLASIFIKASI DECISION TREE DENGAN ALGORITMA C4.5 DALAM PENGAMBILAN KEPUTUSAN PERMOHONAN KREDIT OLEH DEBITUR (STUDI KASUS: BANK PASAR DAERAH ISTIMEWA YOGYAKARTA)," e-Proceeding of Engineering | Fakultas Informatika, Vols. Vol.2,, p. Page 1768, April 2015.

[9] H. Widayu, S. D. Nasution, N. Silalahi and M. , "DATA MINING UNTUK MEMPREDIKSI JENIS TRANSAKSI NASABAH PADA KOPERASI SIMPAN PINJAM DENGAN ALGORITMA C4.5," MEDIA INFORMATIKA BUDIDARMA, Juni 2017, vol. Vol 1, pp. Hal 32-37, Juni 2017.

[10] D. H. Kamagi and S. Hansun, "Implementasi Data Mining dengan Algoritma C4.5 untuk Memprediksi Tingkat Kelulusan Mahasiswa," ULTIMATICS, , Vols. Vol. VI,, pp. 16-17, Juni 2014.

[11] F. F. Harryanto and S. Hansun, "Penerapan Algoritma C4.5 untuk Memprediksi Penerimaan Calon Pegawai Baru di PT WISE," Jatisi, vol. 3, pp. 97-99, 2017.

[12] S. Edhy, Pengantar Teknologi Informasi., Graha Ilmu, 2005.

[13] S. Haryati, A. Sudarsono and E. Suryana, "IMPLEMENTASI DATA MINING UNTUK MEMPREDIKSI MASA STUDI MAHASISWA MENGGUNAKAN ALGORITMA C4.5 (STUDI KASUS: UNIVERSITAS DEHASEN BENGKULU)," Jurnal Media Infotama, vol. Vol. 11, pp. 133-134, September 2015.

[14] S. Priyandae, Mudahnya Belaar Microsoft Excel 2013 Untuk Pemula, Yogyakarta, 2014. 